\section{Response to: 'Successful treatment of plasma exchange for refractory systemic juvenile idiopathic arthritis complicated with macrophage activation syndrome and severe lung disease' by Sato et al}

We were very interested to read the correspondence from Dr. Sato and colleagues describing a case of systemic juvenile idiopathic arthritis (sJIA) with associated diffuse lung disease. ${ }^{1}$ The patient in this new report shares a number of features with cases occurring after exposure to interleukin (IL)-1 or IL-6 inhibitors $(\mathrm{n}=46)$ that we recently detailed in an international case series. ${ }^{2}$ Lung disease complicating sJIA remains a clinical challenge with significant mortality, and we thank the authors for sharing their experience.

One of the typical features of this type of lung disease, as illustrated by this case report, is minimal respiratory symptoms despite significant abnormalities on chest CT. The predominant chest CT pattern in our series, as observed in this case, is septal thickening with or without ground-glass opacities, sometimes together with peribronchovascular consolidation. Also like the patient in this report, a majority of cases in our series had refractory sJIA. However, a significant number $(\sim 40 \%)$ responded to initial treatment, indicating that refractory sJIA is not a prerequisite for lung disease. ${ }^{2}$ Another characteristic, shared by a subset of cases in our series and the current case, is the development of overt macrophage activation syndrome (MAS) at lung disease detection without a prior history of MAS. This finding raises the still unanswered question as to whether parenchymal lung disease stimulates MAS or whether a shared pathway of innate immune dysfunction drives both this new lung disease and MAS.

There are limited data on the efficacy of plasmapheresis for the treatment of MAS and other secondary hemophagocytic lymphohistiocytoses, ${ }^{3}$ and this is the first use of this approach in sJIA with lung disease to our knowledge. The possibility that circulating factors drive MAS and lung disease in the reported patient is suggested by his positive response to plasma exchange. Whereas a number of cytokines are strongly implicated in MAS, ${ }^{45}$ cytokines contributing to the development of lung disease have been suggested but not yet confirmed. ${ }^{67}$ Notably, a set of circulating proteins, including chemokines associated with T-helper 2 responses, are uniquely found in sera from patients with sJIA and lung disease compared with active sJIA or active MAS. ${ }^{8}$ In addition, in our series, progressive lung disease was observed in 17/18 children who had achieved inactive sJIA (on medication), arguing for independent causal factors and possible evolution to a more lung-targeted process. ${ }^{2}$

Prior to the recognition of lung disease, a subset of cases in our series (online supplementary table $S 8^{1}$ ) developed drug reaction with eosinophilia and systemic symptoms (DReSS), an often severe, delayed hypersensitivity reaction. The implicated drugs were IL-1 inhibitors. A patient with sJIA, described by BaderMeunier et al in a recent letter to this journal, ${ }^{9}{ }^{10}$ developed DReSS to canakinumab (monoclonal antibody to IL-1ß) before lung disease diagnosis. Our ongoing collection of cases of sJIA with lung disease (unpublished) includes patients with DReSS to IL-1 inhibitors and patients with DReSS to tocilizumab (antiIL-6 receptor). In the case described by Sato et al, the patient was exposed first to tocilizumab and subsequently to canakinumab. The ensuing MAS and liver enzyme elevation are consistent with a delayed-type drug hypersensitivity reaction, which also can include lung involvement and pancytopenia. ${ }^{11}{ }^{12}$ Importantly, stopping canakinumab and removing residual drug by plasma exchange may have contributed to the improved lung status in this child. Cessation of the implicated drug is key to controlling DReSS progression, along with treatment of any ongoing inflammation that persists after drug withdrawal. ${ }^{13}$

Given the multiple treatments used in this case (and other cases of sJIA with lung disease studied to date), it is difficult to assign sources of improvement with certainty. There are reports of patients with sJIA with lung disease improving after discontinuation of the cytokine inhibitors, as well as during their continued use. ${ }^{1269}$ These varied outcomes may reflect disease heterogeneity, treatment approaches that suppress hypersensitivity reactions or other factors. A key question remains: is parenchymal lung disease that emerges during treatment of sJIA with IL-1 or IL-6 inhibitors triggered by severe delayed drug hypersensitivity, by lung-specific MAS activity or something else? Management decisions hinge on this issue. Organised, controlled testing of treatment strategies, including drug withdrawal and plasma exchange, will contribute to understanding pathogenesis and to identification of best clinical practices.

\section{Vivian E Saper, ${ }^{1}$ Guangbo Chen, ${ }^{2}$ R Paul Guillerman, ${ }^{3}$ Purvesh Khatri, ${ }^{2}$} Randy Q Cron, ${ }^{4}$ Elizabeth D Mellins ${ }^{5}{ }^{5}$

${ }^{1}$ Department of Pediatrics, Stanford University, Stanford, CA, USA

${ }^{2}$ Institute for Immunity, Transplantation and Infection, Center for Biomedical Informatics Research, Department of Medicine, Stanford University, Stanford, California, USA

${ }^{3}$ Department of Pediatric Radiology, Texas Children's Hospital, Houston, Texas, USA ${ }^{4}$ Department of Pediatrics, Division of Rheumatology, University of Alabama at Birmingham, Birmingham, Alabama, USA

${ }^{5}$ Department of Pediatrics, Program in Immunology, Stanford University, Stanford CA, USA

Correspondence to Dr Elizabeth D Mellins, Stanford University, Stanford, CA 94305-5164, USA; mellins@stanford.eduDr Vivian E Saper; vesaper@stanford.edu

\section{Handling editor Josef $S$ Smolen}

Contributors All authors contributed to and agreed on the final version of this response to correspondence.

Funding The authors have not declared a specific grant for this research from any funding agency in the public, commercial or not-for-profit sectors.

Competing interests None declared.

Patient and public involvement Patients and/or the public were not involved in the design, conduct, reporting or dissemination plans of this research.

Patient consent for publication Not required.

Provenance and peer review Not commissioned; externally peer reviewed.

(c) Author(s) (or their employer(s)) 2020. No commercial re-use. See rights and permissions. Published by BMJ.

\section{Check for updates}

To cite Saper VE, Chen G, Guillerman RP, et al. Ann Rheum Dis Epub ahead of print: [please include Day Month Year]. doi:10.1136/annrheumdis-2020-217426

Received 3 April 2020

Accepted 7 April 2020

\section{Linked}

- http://dx.doi.org/10.1136/annrheumdis-2020-217390

Ann Rheum Dis 2020;0:1-2. doi:10.1136/annrheumdis-2020-217426

ORCID iD

Elizabeth D Mellins http://orcid.org/0000-0003-2577-139X

\section{REFERENCES}

1 Sato S, Hosokawa T, Kawashima H. Successful treatment of plasma exchange for refractory systemic juvenile idiopathic arthritis complicated with macrophage activation syndrome and severe lung disease. Ann Rheum Dis 2020. 
2 Saper VE, Chen G, Deutsch GH, et al. Emergent high fatality lung disease in systemic juvenile arthritis. Ann Rheum Dis 2019;78:1722-31.

3 Demirkol D, Yildizdas D, Bayrakci B, et al. Hyperferritinemia in the critically ill child with secondary hemophagocytic lymphohistiocytosis/sepsis/multiple organ dysfunction syndrome/macrophage activation syndrome: what is the treatment? Crit Care 2012;16:R52.

4 Bracaglia C, de Graaf K, Pires Marafon D, et al. Elevated circulating levels of interferon- $\gamma$ and interferon- $\gamma$-induced chemokines characterise patients with macrophage activation syndrome complicating systemic juvenile idiopathic arthritis. Ann Rheum Dis 2017;76:166-72.

5 Eloseily EM, Weiser $\mathrm{P}$, Crayne CB, et al. Benefit of Anakinra in treating pediatric secondary hemophagocytic lymphohistiocytosis. Arthritis Rheumatol 2020;72:326-34.

6 Schulert GS, Yasin S, Carey B, et al. Systemic juvenile idiopathic arthritis-associated lung disease: characterization and risk factors. Arthritis Rheumatol 2019;71:1943-54.

7 de Jesus AA, Hou Y, Brooks S, et al. Distinct interferon signatures and cytokine patterns define additional systemic autoinflammatory diseases. J Clin Invest 2020:130:1669-82.

8 Chen G, Schulert G, De Jesus A, et al. Multiplex serum analysis identifies potential biomarkers of systemic juvenile idiopathic arthritis, macrophage activation syndrome, and associated pulmonary alveolar proteinosis: evidence for Independently-regulated hyperinflammatory and eosinophilic inflammation. Arthritis Rheumatol 2019;71.

9 Bader-Meunier B, Hadchouel A, Berteloot L, et al. Effectiveness and safety of ruxolitinib for the treatment of refractory systemic idiopathic juvenile arthritis like associated with interstitial lung disease : a case report. Ann Rheum Dis 2020.10.1136/annrheumdis-2020-216983. [Epub ahead of print: 13 Feb 2020].

10 Saper VE, Chen G, Khatri P, et al. Response to: 'Effectiveness and safety of ruxolitinib for the treatment of refractory systemic idiopathic juvenile arthritis like associated with interstitial lung disease: case report' by Bader-Meunier et al. Ann Rheum Dis 2020.10.1136/annrheumdis-2020-217000. [Epub ahead of print: 13 Feb 2020].

11 Martínez-Cabriales SA, Rodríguez-Bolaños F, Shear NH. Drug reaction with eosinophilia and systemic symptoms (dress): how far have we come? Am I Clin Dermatol 2019:20:217-36.

12 Lambotte 0, Costedoat-Chalumeau N, Amoura Z, et al. Drug-Induced hemophagocytosis. Am J Med 2002:112:592-3.

13 Choudhary S, McLeod M, Torchia D, et al. Drug reaction with eosinophilia and systemic symptoms (DRESS) syndrome. J Clin Aesthet Dermatol 2013;6:31-7. 